\section{Changing the objectives}

SIR - Your leading article of 7 March (p.1) deals with policies for UK science, including astronomy, in the context of fixed or declining resources. You say: " . . one, or the other, or perhaps both of the observatories must go ....". You suggest that the "good work these laboratories do ... could be transferred intact to universities". Another problem is that experimental facilities have become "institutionalized".

I suggest that a contract-based laboratory might be set up in the general subject area of physical technology, of which astronomical technology would be part. It would absorb some staff and property of the Royal Greenwich Observatory and the Royal Observatory, Edinburgh. It should probably not absorb the Nautical Almanac Office and historical collections of the observatories, which need limited resources and could continue independently.

This suggestion is intended to be more far-reaching than simply merging the observatories. The organization is not going to be a literal observatory because the relevant instruments are overseas. It is more of a research and development organization, a design office and a workshop. Although such a new laboratory would start by working on instruments for astronomy, that need be only one of its jobs. There seems little to be gained from total specialization. The aim would be to add versatility and university contacts and to give the establishment responsibility for its own fate. Versatility in the face of change is relevant to present circumstances. There could be many other gains. Developments in one area of technology such as astronomical instrumentation need inputs from other subjects and in turn ought to be generally disseminated - that process would also be helped. A vigorous working environment is foreseeable.

The question must be asked: would such a laboratory take money or talent needed elsewhere? The answer must lie in the way it is run. Its income would not be unfair if it was gained by offering a service that could be refused. Such operations would be based on contracts.

For a new laboratory, the foundation itself could take the form of a contract or agreement between the Department of Education and Science and the management authority, which could be a university. A notable example is the vast Jet Propulsion Laboratory in Pasadena, which is managed by the California Institute of Technology on a contract. To maintain the service principle, the foundation agreement itself should not provide much of the running expenses for technology. The foundation could reasonably support some scientists. The research councils should probably not be legally involved in the foundation as the laboratory would be one of their contractors.
It should be appreciated that the observatories' research astronomers are few in number and their continued support is not a problem that can relevantly be compared with that of providing and operating the larger research facilities which are basically for universities. The practice of astronomy has been the attractive feature of the observatories for many staff who have eventually worked in technology. The total contribution of the observatories' astronomers to the provision of facilities, as well as to the provision of fundamental data and to research programmes, is such that they can surely be included in the framework proposed. Some posts would be part of the foundation agreement, some would be Science and Engineering $\mathrm{Re}$ search Council (SERC) fellowships applied for in the usual way, some posts including direct responsibility for instrumentation would be supported by contracts. It would be open to the organization to use any net income to employ extra scientists.

Such a laboratory would be clearly distinguishable from others. The differences would be in the combination of the university connection, contract operation, flexibility in the type of work, the laboratory and the university together seeking work

\section{Plight of refusniks}

SIR - Ten years ago, on 12 March 1975 , my family applied for exit visas from the Soviet Union for the first time. I was immediately removed from my position in the mathemetical department of the Institute for Chemical Physics of the Academy of Sciences of the USSR. At the same time, a total boycott was organized against my family in the scientific centre of the academy in Chernogolovka.

For ten years I have been prohibited from attending seminars, conferences and symposia. Correspondence from abroad is not delivered to me. I do not receive scientific journals, including those of the American Physical Society and the American Mathematical Society. The Academy of Sciences presses my foreign colleagues to abandon attempts to meet me and then to take part in the scientific boycott against me.

For ten years we have been stubbornly making efforts to get exit visas. In 1979, representatives of the academy, academician N. Emanuel, Academician N. Semenov and others, officially stated that the academy had no objections to my departure, and we were informed that the Soviet leaders had made an official decision to give our family exit visas. But this decision has not been implemented.

My numerous meetings with the general secretary of the academy, Academician G. Scrjabin, showed that the academy blocked the fulfilment of this decision.

The situation has abruptly become worse @ 1985 Nature Publishing Group and the origins in astronomical technology (mainly optics, detectors, computing and mechanical engineering).

The operation of existing research facilities and building of new ones would be on the basis of a number of separate long or short-term contracts. Scientists requiring such work would probably act through SERC, using either a grant or a direct contract from the council for common facilities. Ultimately, these contracts could be placed or not as required and could be refused by the laboratory: cancellation would be regulated by the contract.

The laboratory would therefore have the need and the opportunity to support itself (as distinct from subsidizing the facilities). This it would do by seeking government and commercial work which should not be circumscribed. The laboratory could sell its services, software and the rights to its inventions.

From the scientists' point of view, much would depend on the continuing goodwill of the managing university. Success would depend on the local management and staff, and sanctions would be available through the contracts.

RICHARDG. BINGHAM

Brackenholme,

Jenners Lane,

Wartling, Hailsham,

East Sussex BN27 IRU, UK

after negotiations between the Academy of Sciences of the USSR and the National Academy of Sciences of the United States. Academician Scrjabin and Academician Yu. Ovchinnikov, a vice president of the academy, immediately refused to discuss my problem with me. And Academician E. Velikhov, another vice president of the academy, refused even to speak with me.

SOLOMON AL'BER

Moscow, Soviet Union.

\section{Abstract policy}

SIR - In regard to the previous correspondence on the abstract policy of the Biosciences Information Service (BIOSIS) $(\mathbf{H}$ E. Kennedy, Nature 310, 96; 1984), I would agree with those favouring their inclusion. I would point out, however, that the only thing worse than no abstract is a reference to one when there is no obvious way of obtaining a copy. BIOSIS apparently does not intend to offer OATS (original article tear-sheet service) as does the Chemical Abtracts Service.

Would it be too much to ask that some record be provided as to which libraries hold these abstract volumes in a manner similar to CASSI (Chemical Abstracts Service Source Index) or that they be deposited in the British Library Lending Division or a library which reports its holdings to the Online Computer Library Center?

DANA L. ROTH

Science and Engineering Libraries, California Institute of Technology, Pasadena, California 91125, USA 